\title{
Evaluation of Physical, Milling and Cooking Properties of Four New Rice (Oryza Sativa L.) Varieties in Nigeria)
}

\author{
Mayowa S. Sanusi $^{\mathrm{a}^{*}}$, Rahman Akinoso ${ }^{\mathrm{a}}$, And Nahemiah Danbaba ${ }^{\mathrm{b}}$ \\ ${ }^{a}$ Department of Food Technology, Faculty of Technology, University of Ibadan, Nigeria \\ b Food Technology and Value Addition Programme, National Cereal Research Institute, Baddeggi, Nigeria \\ ${ }^{*}$ Corresponding author \\ sanusimayowa@gmail.com \\ TEL: +2348069430996
}

Received: 7 March 2017; Published online: 18 October 2017

\begin{abstract}
This comparative study investigated some physical, milling and cooking properties of four new rice varieties (FARO 44, FARO 52, FARO 60 and FARO 61) in Nigeria. The varieties were processed into white rice and their properties analyzed separately using standard procedures. Results showed that paddy length, paddy-length-to-width-ratio, equivalent diameter, sphericity, grain volume, aspect ratio, thousand paddy grain weight, milled rice length, milled rice width, milled rice length to width ratio, milling recovery, head milled rice, broken milled rice, $\mathrm{L}^{*}, \mathrm{a}^{*}, \mathrm{~b}^{*}$, elongation ratio, cooked-rice-lengthto-breadth-ratio, water uptake ratio and cooking time were significantly different $(\mathrm{p}<0.05)$ for all the varieties. Milling recovery was found to vary from 65.3 to $68.33 \%$; with FARO 60 having the highest head milled rice. It was observed that FARO 44 had the longest cooking time, elongation ratio and cooked rice length/breadth ratio while FARO 61 was found to have the highest water uptake ratio. There was significant positive correlation $(\mathrm{r}=0.824)$ between percentage head milled rice and milling recovery while negative correlation existed between cooking time and $L^{*}(r=-0.711)$. This information could be exploited by rice processors in the post-harvest processing of the varieties.
\end{abstract}

Keywords: Rice varieties; White rice; Physical properties; Milling properties; Cooking properties

\section{Introduction}

Rice (Oryza sativa L.) is one of the most consumed cereals in the world and is a staple food for more than half of the world population. In Nigeria, rice production and consumption represent a significant part of the government strategy to overcome food shortage and improve food self-sufficiency for both local consumption and the export trade (Danbaba et al., 2012). Rice is a regular component of the African diet, usually consumed as a whole grain; which contributes more to the total calorie intake. In the major rice consuming countries, rice quality dictates the market value of the commodity and plays an important role in the development and adoption of new varieties (Juliano, 2003; Fitzgerald, McCouch, \& Hall, 2009). A significant variation in physical, milling and cooking quality has been shown among rice varieties produced in different parts of world due to diverse genetic and environmental factors (Singh, Kaur, Sodhi, \& Sekhon, 2005; Izawa, 2008). Rice variety development programmes have led to tremendous progress in the development of rice varieties that have good agronomical properties, in terms of their resistance to abiotic and biotic stress and high yielding potential. In an attempt to maximize the quality of the rice varieties, information on physical, milling and cooking properties of the vari- 
246 | Sanusi et al.

eties is vital to ensure good post-harvest processing.

Physical properties of rice varieties are important factors that have to be considered when designing equipment for handling, conveying, separation, dehusking, drying and storage. The grain weight, diameter, surface area, bulk density, thickness, length and width of rice variety have to be factored into the design and optimal performance of grain threshing machines (Simonyan, El-Okene, \& Yiljep, 2007). The principal axial dimension of grain is useful in power calculation for milling and in selecting sieve sizes for optimal separation (Singh, Kaur, \& Singh, 2015), while bulk density values are useful in determining the size of grain hoppers and storage facilities.

Milling is an important unit operation in rice processing as the accuracy of milling largely determines the market value. Milling consists of the removal of husk and bran to obtain the edible portion (endosperm) to a level that is acceptable and fit for human consumption (Singh et al., 2015). The key quality determinant of rice are, a large percentage of whole or head rice, high milling recovery, low broken rice, absence of impurities, and good appearance. Cooking is a unit operation that involves the heating of food to make it edible and suitable for consumption. The cooking quality of rice that also determines its economic value can be measured in terms of cooking time, grain elongation ratio, water uptake ratio and cooked length breadth ratio. Cooking time is important since it determines tenderness of cooked rice as well as stickiness to a great extent (Anonymous, 1997).

Therefore, as a strategy to complement the effort of the rice breeders in rice research programme, it is imperative to evaluate some physical, milling and cooking properties of the rice varieties to know their inherent properties, as this will influence their post-harvest handling. Hence the objective of present study was to evaluate some physical, milling and cooking properties of four new rice varieties in Nigeria.

\section{Materials and Methods}

\subsection{Sample preparation}

The paddy grains (FARO 44, FARO 52, FARO 60 and FARO 61) used in this study were obtained from National Cereals Research Institute Baddegi, Nigeria and analyzed in the grain quality control laboratory of Food Technology and Value Addition Programme of the same institute. The paddy grains were cleaned to remove foreign matter such as stones, straw and dirt. The moisture of the paddy grains were conditioned to $12 \pm 1 \%$ (wb) for each variety. A digital grain moisture meter (Riceter model F506, Taiwan) was used to determine the moisture in wet basis (wb). Three replicates each $500 \mathrm{~g}$ of cleaned paddy grains were dehusked in a THU35B Satake testing rice husker (Satake, Japan). The resulting brown rice varieties were polished using a Satake grain testing mill TM05 (Satake, Japan) to obtain white rice.

\section{$2.2 \quad$ Physical properties}

\section{Grain dimension}

Twenty selected paddy grains of each of the rice varieties were randomly selected for measurement of their principal axial dimensions; length (L), width (W) and thickness (T) using a digital vernier caliper (Model AD-5765-100) as shown in figure 1. Shape here referred to as length-width ratio was calculated using equation 1 . The process was replicated for milled rice. Mean of measurement were recorded as data.

$$
L / W=\frac{L}{W}
$$

where $\mathrm{L} / \mathrm{W}$ is the length-to-width ratio of the paddy or milled rice, $\mathrm{L}$ is length of paddy or milled rice $(\mathrm{mm})$ and $\mathrm{W}$ is width of paddy or milled rice $(\mathrm{mm})$. 


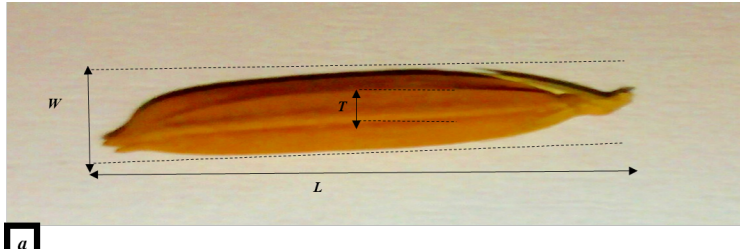

田

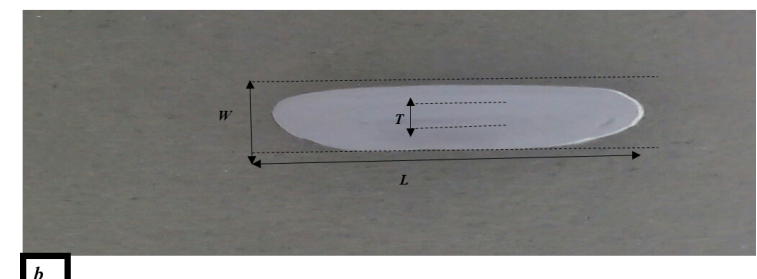

Figure 1: The dimensions of paddy grain and white rice (a) Represent paddy grain (b) white rice

\section{Equivalent diameter $\left(\mathbf{D}_{e}\right)$}

The prolate spheroid shape of the grains was used to determine the equivalent diameter (De) as expressed in equation 2 (Mohsenin, 1970; Jain \& Bal, 1997).

$$
D e=\left(\frac{L(W+T)^{2}}{4}\right)^{\frac{1}{2}}
$$

where $D e$ is equivalent diameter $(\mathrm{mm})$ and $\mathrm{T}$ is thickness of paddy or milled rice $(\mathrm{mm})$.

\section{Sphericity $(\varnothing)$}

The sphericity $(\varnothing)$ is defined as the ratio of the surface area of the sphere having the same volume as that of grain to the surface area of the grain (Mohsenin, 1970). It was determined using equation 3 .

$$
\varnothing=\frac{(L W T)^{1 / 3}}{L}
$$

\section{Grain volume (V)}

The volume (V) of grains were determined using equation 4 (Jain \& Bal, 1997).

$$
V=0.25\left(\frac{\pi}{6} L(W+T)^{2}\right)
$$

\section{Surface area (SA)}

Surface area (SA) of the paddy of each variety was determined using the equation 5 (Jain \& Bal, 1997).

$$
S A=\frac{\pi L \sqrt{W T}}{2 L-\sqrt{W T}}
$$

\section{Aspect ratio ( $\mathrm{Ra})$}

The aspect ratio ( $\mathrm{Ra}$ ) of was expressed using equation 6 (Varnamkhasti et al., 2008).

$$
R a=\frac{W}{L}
$$

where $\mathrm{R}_{a}$ is aspect ratio, $\mathrm{W}$ is width $(\mathrm{mm})$ and $\mathrm{L}$ is length (mm).

\section{Bulk density}

The bulk density $(\rho b)$ is defined as the ratio of the mass of sample to its total volume and was determined using equation 7.

$$
\rho b=\frac{M p}{V}
$$

where $\mathrm{M}_{p}$ is the mass of paddy grains in gram (g) and $\mathrm{V}$ is the volume occupied in $\mathrm{cm}^{3}$.

\section{Thousand paddy weight (1000P)}

The thousand paddy weight was determined by randomly selecting one thousand paddy grains of each of the varieties, weighed and recorded separately (Varnamkhasti et al., 2008).

\subsection{Milling properties}

\section{Milling recovery (MR)}

The milling recovery (MR) was estimated by dividing the weight of milled rice recovered by the weight of the paddy using equation 8 :

$$
M R=\frac{W M R}{W P} \times 100
$$

where $\mathrm{MR}$ is milling recovery (\%), WMR is weight of milled rice $(\mathrm{g})$ and $\mathrm{WP}$ is weight of paddy $(\mathrm{g})$. 


\section{Head milled rice (HMR)}

The broken grains were separated from the whole grains. The head milled rice was expressed using equation 9 (Ravi, Menon, Gomathy, Parimala, \& Rajeshwari, 2012).

$$
H M R=\frac{W H M R}{W P} \times 100
$$

where HMR is the head milled rice (\%), WHMR is weight of head milled rice (g) and WP is weight of paddy $(\mathrm{g})$.

\section{Broken milled rice (BMR)}

The broken milled rice (BMR) was expressed using equation 10 (Firouzi, Alizadeh, \& Minaei, 2010).

$$
B M R=\frac{W B M R}{W P} \times 100
$$

where BMR is the broken milled rice (\%), WBMR is weight of broken milled rice $(\mathrm{g})$ and $\mathrm{WP}$ is weight of paddy $(\mathrm{g})$.

\section{Color determination}

Color of the milled rice were determined using a Konica Minolta digital colorimeter (Model CR10, Konica Minolta optics, Japan); with the color of the samples represented by $\mathrm{L}^{*}, \mathrm{a}^{*}$ and $\mathrm{b}^{*}$. The $\mathrm{L}^{*}$ value gives a measure of product lightness and ranges from absolute black to absolute white, $\mathrm{a}^{*}$ value represent red to green color of the samples and ranges from negative value on the red side to positive on the green side and $b^{*}$ value showed mixed blue-yellow color of the samples and ranges from negative value on the blue side to positive value on the yellow side.

\subsection{Cooking properties}

\section{Cooking time}

Milled rice samples of $10 \mathrm{~g}$ of each variety were cooked in $100 \mathrm{ml}$ of water at temperature of $100^{\circ} \mathrm{C}$ on an electric cooker (Toshiba, Model RC18R). After cooking for $10 \mathrm{~min}$, samples were taken at every $2 \mathrm{~min}$ intervals for testing until the end of the cooking cycle. Ten cooked grains were randomly taken and pressed between two clean glass plates. Cooking time was recorded for each variety when at least $90 \%$ of the grains no longer had opaque core or uncooked centers.

\section{Elongation ratio $\left(\mathbf{E}_{r}\right)$}

Elongation ratio was determined by randomly selecting twenty cooked rice samples and measured for length. The mean measured length of cooked rice were divided by mean length of uncooked raw samples. The elongation ratio was expressed using equation 11.

$$
E_{r}=\frac{L_{1}}{L_{0}}
$$

where $L_{0}$ is length of uncooked rice and $L_{1}$ length of cooked rice.

\section{Cooked rice length/breadth ratio $\left(\mathbf{C}_{l w}\right)$}

The length/breadth ratio was determined by dividing the cumulative length to breadth ratio of cooked rice. A mean of twenty replicates were taken for measurement. The cooked rice lengthbreadth ratio was expressed using equation 12 .

$$
C_{l b}=\frac{L_{c}}{B_{c}}
$$

where $\mathrm{C}_{L b}$ is length to breadth ratio of cooked rice, $\mathrm{L}_{c}$ is length of cooked rice and $\mathrm{B}_{c}$ is breadth of cooked rice.

\section{Water uptake ratio (WUR)}

This was determined by cooking $10.0 \mathrm{~g}$ of whole rice of each variety in $100 \mathrm{ml}$ of water for a minimum cooking time on an electric cooker (Toshiba, Model RC-18R). The cooked samples were weighed accurately and the water uptake ratio was determined using equation 13 .

$$
W U R=\frac{W C R}{W U C R}
$$

where WUR is water uptake ratio, WCR is the weight of cooked rice (g) and WUCR is the weight of uncooked rice (g). Similar method was reported by Oko and Ubi (2012). 


\subsection{Statistical analysis}

The data were analyzed using SPSS software (version 20) and spread sheet of Microsoft excel. Analysis of variance (ANOVA) of means was conducted using Duncan's multiple tests. Differences were declared statistically significant when $P<0.05$. Interrelationship between the physical, milling and cooking properties was examined using the Pearson correlation coefficient.

\section{Results and Discussion}

\subsection{Physical properties}

The physical properties of the rice varieties are presented on Table 1. For the analyzed paddy Length, a significant difference between the varieties was observed at $\mathrm{p}<0.05$. However, there was no significant difference in the width and thickness of the paddy of the varieties. Also, there was no significant difference $(p>0.05)$ in the paddy length to width ratio of FARO 41, 52 and 61 expect for FARO 60. A similar trend was observed in the milled rice length, width, thickness and length-to-width ratio of the rice varieties as shown in table 2 . The difference observed in the varieties could be traced to individual properties. Different investigations also reported the wide range of grain dimensions while studying with different rice varieties (Correa, da Silva, Jaren, Afonso Junior, \& Arana, 2007; Danbaba et al., 2012; Shittu, Olaniyi, Oyekanmi, \& Okeleye, 2012; Mir, Bosco, \& Sunooj, 2013). The length, width and thickness of the varieties are important in designing and selecting sieve separators and in calculating power during rice milling (Varnamkhasti et al., 2008).

Table 4 , showed positive correlation $(\mathrm{r}=0.626)$ existed between paddy length and paddy length to width ratio, negative correlation $(\mathrm{r}=-0.639)$ existed between paddy width and paddy length to width ratio. Also, negative correlation ( $\mathrm{r}=$ -0.566) was found between paddy thickness and paddy length to width ratio. This implies that as the paddy length increases, the length to width ratio increases while a decrease in paddy thickness and width increases length-to-width ratio. The length-to-width ratio of paddy varied from
4.43 (FARO 44) to 4.74 (FARO 61) while for milled rice ranged between 3.09 (FARO 44) to 3.52 (FARO 61). The values of length-to widthratio is useful in determining the shape of the variety. According to Mckenzie and Rutger (1983) cooking and eating qualities of rice are strongly influenced by shape and width of grains, hence determining the length to width ratio and width of grain is essential. The type of size and shape of the paddy and milled rice of each variety ware determined using IRRI - International Rice Research Institute (1980) classification. For size, very long is ( $>7.5 \mathrm{~mm}$ in length), long is $(<6.61$ $\mathrm{mm}$ in length), medium is (5.51 to $6.6 \mathrm{~mm}$ in length) and short is ( $<5.50 \mathrm{~mm}$ in length). While for length to width ratio, slender is (ratio $>3.0)$, medium is $(2.1$ to 3 ), bold is (1.1 to 2 ) and round is (ratio $<1.0)$. Based on the aforementioned classification, results from table 1 and 2 showed that the varieties were found to be very long-slender paddy and medium-slender milled rice.

The equivalent diameter and sphericity of the varieties differ significantly $(\mathrm{p}<0.05)$. The mean equivalent diameters varied from 3.12 (FARO 52) to $3.30 \mathrm{~mm}$ (FARO 60 ). The least sphericity $(33.78 \%)$ was in FARO 61 and highest in FARO $44(35.53 \%)$. The variation might be due to the physical shape of the paddy, which has pointed tips along the length axis thereby increasing their characteristic length compared to the FARO 44 with more rounded tips. Similar findings were reported by Thakur and Gupta (2006) and Mir et al. (2013). Paddy grains with lower sphericity will likely be more difficulty to roll freely on a flat surface. The ability to either roll or slide is necessary in the design of hoppers for milling process. Aspect ratio distribution determination is important in classifying the varieties and determine the extent of off-size in market grade (Varnamkhasti et al., 2008). The aspect ratio was found to be lowest in FARO 61 (0.21) and highest in FARO 60 (0.23). The aspect ratio of the varieties were found to differ significantly $(\mathrm{p}<0.05)$ only in FARO 60. The mean aspect ratios were found in the range of 0.21 to 0.28 for paddy varieties as reported in literature (Varnamkhasti et al., 2008). Significant differences were observed in the paddy volume but there was no significant differences in their surface area. Mean paddy 
Table 1: Physical properties of the rice varieties

\begin{tabular}{|c|c|c|c|c|}
\hline Physical properties & FARO 44 & FARO 52 & FARO 60 & FARO 61 \\
\hline Paddy length (mm) & $8.99 \pm 0.60^{b}$ & $8.83 \pm 0.46^{b}$ & $9.48 \pm 0.57^{a}$ & $9.59 \pm 0.64^{a}$ \\
\hline Paddy width (mm) & $2.05 \pm 0.17^{a}$ & $2.01 \pm 0.17^{a}$ & $2.11 \pm 0.12^{a}$ & \\
\hline Paddy thickness (mm) & $1.77 \pm 0.18^{a}$ & $1.71 \pm 0.14^{a}$ & $1.80 \pm 0.11^{a}$ & $1.74 \pm 0.09^{a}$ \\
\hline Paddy length to width & $4.43 \pm 0.41^{b}$ & $4.42 \pm 0.43^{b}$ & $4.52 \pm 0.37^{a b}$ & $4.74 \pm 0.32^{b}$ \\
\hline Equivalent diameter (mm) & $3.19 \pm 0.24^{a b}$ & $3.12 \pm 0.17^{b}$ & $3.30 \pm 0.13^{b}$ & $3.24 \pm 0.14^{a b}$ \\
\hline Sphericity $(\%)$ & $35.53 \pm 2.23^{a}$ & $35.36 \pm 2.27^{a}$ & $34.86 \pm 1.86^{a b}$ & $33.78 \pm 1.60^{b}$ \\
\hline Grain volume $\left(\mathrm{mm}^{3}\right)$ & $17.37 \pm 4.25^{a b}$ & $16.08 \pm 2.79^{b}$ & $18.97 \pm 2.29^{a}$ & $17.86 \pm 2.24^{a b}$ \\
\hline $\mathrm{a}\left(\mathrm{mm}^{2}\right)$ & $3.35 \pm 0.36^{a}$ & $3.26 \pm 0.29^{a}$ & $3.41 \pm 0.21^{a}$ & $3.27 \pm 0.18^{a}$ \\
\hline Aspect ratio & $0.23 \pm 0.02^{a}$ & $0.23 \pm 0.02^{a}$ & $0.23 \pm 0.019^{a b}$ & $0.21 \pm 0.01^{b}$ \\
\hline Thousand paddy weight (g) & $24.24 \pm 1.40^{c}$ & $22.98 \pm 1.24^{b}$ & $27.24 \pm 1.19^{a}$ & $24.46 \pm 1.10^{b}$ \\
\hline Bulk density $\left(\mathrm{g} \mathrm{cm}^{-3}\right)$ & $0.88 \pm 0.03^{a}$ & $0.88 \pm 0.05^{a}$ & $0.89 \pm 0.04^{a}$ & $0.87 \pm 0.04^{a}$ \\
\hline
\end{tabular}

Mean values in the same rows bearing the same superscript do not differ significantly $(\mathrm{p}<0.05)$.

volume values ranged from 16.08 (FARO 51) to $17.86 \mathrm{~mm}^{3}$ (FARO 61). The paddy volume and surface area in this study were almost similar to those reported for Sorkheh and Sazandegi varieties (Varnamkhasti et al., 2008). The effects of surface area on drying rates of particulate materials can also be characterized by using the surface to volume ratio (Mir et al., 2013). Also, the ratio of surface area to volume affects drying time and energy requirements (Zareiforoush, Hosseinzadeh, Adabi, \& Motavali, 2011).

The bulk density values showed that there were no significant $(\mathrm{p}>0.05)$ differences among the varieties, this may be due to the inherent characteristics of the varieties. Among varieties studied, FARO 60 has the highest bulk density 0.89 $\mathrm{g} \mathrm{cm}^{-3}$ and FARO $61\left(0.87 \mathrm{~g} \mathrm{~cm}^{-3}\right)$ was found to have the lowest. Bulk density values are useful in design of silos and storage bins (Nalladurai, Alagusundaram, \& Gayathri, 2002). Since bulk density of FARO 61 was the lowest, this implies that FARO 61 will require large silos compared to other varieties. Similar results were reported by Correa et al. (2007) for Urucuia, Confianca, and Jequitiba varieties and Zareiforoush, Komarizadeh, and Alizadeh (2009) for Alikazemi and Hashemi varieties. Correlation studies between the physical properties and milling properties as shown in table 4 , revealed a significantly $(\mathrm{p}<0.05)$ positive correlation between milling recovery and a thousand paddy weight $(\mathrm{r}=0.543)$ which indicate that milling recovery increases with increase in a thousand paddy weight. Thousand paddy weight showed significant variation $(\mathrm{p}<0.05)$ and varied from 22.98 to $27.24 \mathrm{~g}$. FAR0 60 has the highest thousand grain weight and FARO 52 has the lowest. These values were similar to those investigated by Mir et al. (2013). Thousand paddy weight is a useful index in determining milling outturn, in measuring relative amount of dockage in paddy, shriveled kernels and weight proportion of the paddy constituted by the husk.

\subsection{Milling properties}

Table 2 presented the result of the milling properties of the varieties. A significant difference was observed between the milling recovery and head milled rice of the varieties $(\mathrm{p}<0.05)$. The milling recovery ranges from $65.30 \%$ (FARO 52 ) to $68.36 \%$ (FARO 44) while the broken milled rice ranges between $18.92 \%$ (FARO 60 ) to $53.77 \%$ (FARO 61). Head milled rice ranges between $12.74 \%$ (FARO 61) and 47.96\% (FARO 60). Also, there was significant difference in broken milled rice of the varieties tested. A high level of breakage was observed in FARO 61. The differences in the head milled rice and broken milled rice can be attributed to the different behaviors of the varieties during separation of husk and bran from the kernel. These behaviors are caused by grain size, porosity of starch granules and 
Properties of four new rice varieties in Nigeria | 251

Table 2: Milling properties of the rice varieties

\begin{tabular}{lcccc}
\hline Milling properties & FARO 44 & FARO 52 & FARO 60 & FARO 61 \\
\hline Milled rice length (mm) & $6.14 \pm 0.35^{b}$ & $6.10 \pm 0.33^{b}$ & $6.40 \pm 0.41^{a}$ & $6.43 \pm 0.25^{a}$ \\
Milled rice width (mm) & $2.0 \pm 0.19^{a}$ & $1.83 \pm 0.15^{b}$ & $1.93 \pm 0.13^{a b}$ & $1.84 \pm 0.16^{b}$ \\
Milled length to width ratio & $3.09 \pm 0.34^{c}$ & $3.35 \pm 0.23^{b}$ & $3.33 \pm 0.27^{b}$ & $3.52 \pm 0.24^{a}$ \\
Milled recovery (\%) & $68.36 \pm 0.66^{a}$ & $65.30 \pm 0.19^{c}$ & $68.27 \pm 0.12^{a}$ & $67.40 \pm 0.20^{b}$ \\
Head milled rice (\%) & $46.86 \pm 0.65^{c}$ & $22.28 \pm 0.12^{d}$ & $47.96 \pm 0.0^{b}$ & $12.74 \pm 0.06^{d}$ \\
Broken milled rice (\%) & $20.62 \pm 0.33^{b}$ & $20.14 \pm 0.28^{a}$ & $18.92 \pm 0.0^{c}$ & $53.77 \pm 0.17^{a}$ \\
$\mathrm{~L}^{*}$ & $22.37 \pm 2.08^{d}$ & $20.14 \pm 1.73^{c}$ & $17.08 \pm 1.55^{b}$ & $15.99 \pm 1.43^{a}$ \\
$\mathrm{a}^{*}$ & $1.33 \pm 0.52^{b}$ & $1.71 \pm 0.39^{c}$ & $2.44 \pm 0.41^{d}$ & $0.39 \pm 0.51^{a}$ \\
$\mathrm{~b}^{*}$ & $22.31 \pm 1.27^{b}$ & $19.96 \pm 1.38^{c}$ & $18.15 \pm 0.63^{a}$ & $23.82 \pm 0.69^{a}$ \\
\hline
\end{tabular}

Mean values in the same rows bearing the same superscript do not differ significantly $(\mathrm{p}<0.05)$.

Table 3: Cooking properties of the rice varieties

\begin{tabular}{lcccc}
\hline Cooking Properties & FARO 44 & FARO 52 & FARO 60 & FARO 61 \\
\hline Elongation ratio & $1.64 \pm 0.14^{a}$ & $1.49 \pm 0.14^{b}$ & $1.63 \pm 0.12^{a}$ & $1.36 \pm 0.17^{c}$ \\
Cooked length to breadth & $3.51 \pm 0.44^{a}$ & $3.37 \pm 0.38^{a}$ & $3.46 \pm 0.40^{a}$ & $3.26 \pm 0.48^{a}$ \\
Water uptake ratio & $2.68 \pm 0.28^{a}$ & $3.37 \pm 0.16^{b}$ & $3.55 \pm 0.11^{c}$ & $3.87 \pm 0.02^{d}$ \\
Cooking time (min) & $21.5 \pm 1.54^{a}$ & $18.35 \pm 0.49^{b}$ & $17.35 \pm 0.49^{c}$ & $15.65 \pm 0.49^{d}$ \\
\hline
\end{tabular}

Mean values in the same rows bearing the same superscript do not differ significantly $(\mathrm{p}<0.05)$.

presence of fissures. Wiset, Srzednicki, Driscoll, Nimmuntavin, and Siwapornak (2001) reported that rice varieties with longer size are more susceptible to cracking and breakage during milling. Also, Wozniak (2001) stated that fissured grains are characterized by reduced mechanical strength and their tendency to crumble during postharvest processing is easier than grains no such damage. FARO 60 have the highest head milled rice of $47.96 \%$. However, Dipti, Bari, and Kabir (2003) reported that a good quality rice will have a head rice yield of at least $70 \%$. It can be deduced that out of the four varieties, FARO 44 and FARO 60 have an intermediate quality in terms of head milled rice while FARO 52 and FARO 61 have low quality head milled rice while processing to white rice. From table 4, significant positive correlations $(\mathrm{p}<0.01)$ existed between milling recovery and head milled rice ( $\mathrm{r}$ $=0.824)$ while a significant negative correlation $(\mathrm{p}<0.05)$ was found between milling recovery and broken milled rice $(\mathrm{r}=-0.804)$ which implies that decrease in milling recovery leads to increase in broken milled rice.

Significant differences $(\mathrm{p}<0.05)$ were observed between color parameters; L, a*, b* among the rice varieties as shown in table 2 . In terms of lightness, FARO 44 was found to have the highest value $\left(\mathrm{L}^{*}=22.37\right)$ while the least was FARO $61\left(\mathrm{~L}^{*}=15.99\right), \mathrm{a}^{*}$ value was highest in FARO 60 (2.44), while the lowest $b^{*}$ value was observed in FARO 61 (0.39). For b* value, FARO 61 (23.82) was the highest while the lowest was in FARO 60 (18.15). The genetic makeup and colored pigment of the varieties might be responsible for the differences in the color of the rice kernel (Aboubakar, Njintang, Scher, \& Mbofung, 2008; Kaur, Kaushal, \& Sandhu, 2013). 3.3 Cooking properties Table 3 summarized the cooking properties of the rice varieties. There was a significant difference $(\mathrm{p}<0.05)$ between the cooked length and cooked breadth of the rice varieties, with FARO 60 having the longest cooked length $(10.39 \mathrm{~mm})$ and breadth $(3.03 \mathrm{~mm})$ respectively. Lengthwise increase during cooking is preferred and is characteristic of a high quality rice va- 
252 | Sanusi et al.

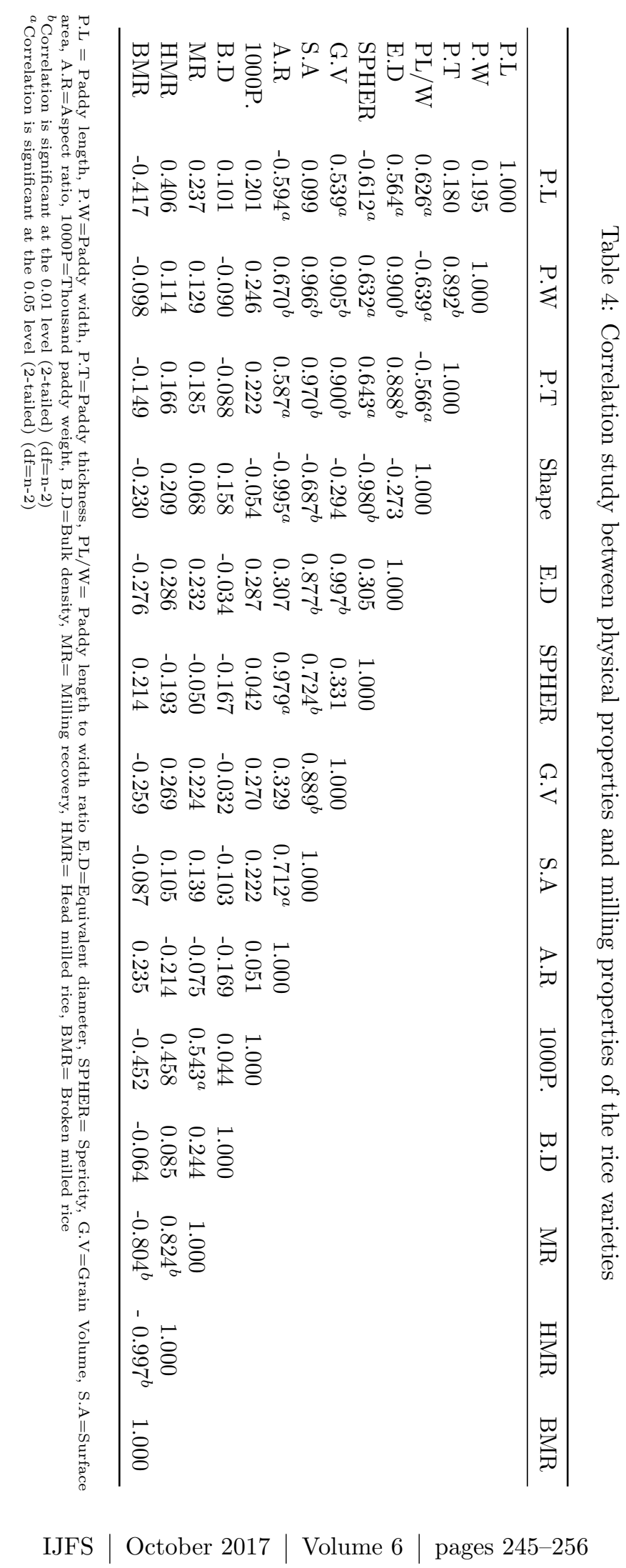




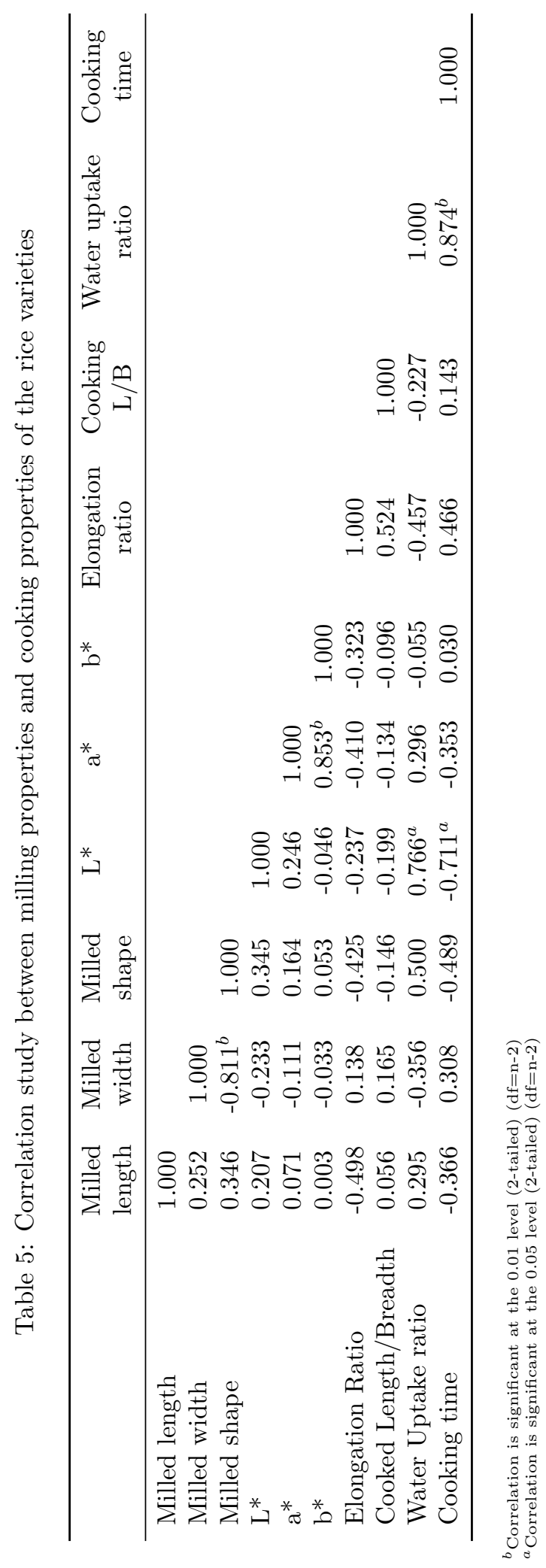

IJFS | October 2017 | Volume 6 | pages 245-256 
riety while increase in breadth is considered as an undesirable trait (Danbaba, Anounye, Gana, Abo, \& Ukwungwu, 2011). The varietal differences showed significant $(\mathrm{p}<0.05)$ effect on elongation ratio and it ranged from 1.36 to 1.64. Danbaba et al. (2011) reported that cooked length to breadth ratio and amylose content influences the elongation ratio of rice. FARO 44 has the highest cooked length to breadth ratio (3.51) and hence the highest elongation ratio. Similar findings were reported by Rather, Malik, and Dar (2016).

There were significant differences $(\mathrm{p}<0.05)$ between the cooking time of the varieties. The cooking time varied between 15.65 minutes and 21.5 minutes with FARO 60 having the least cooking time. This could be attributed to their gelatinization temperature since gelatinization temperature contributes directly to the cooking time of rice. Water uptake ratio obtained for the rice varieties were comparable with the values reported by Oko and Ubi (2012) and Frei, Siddhuraju, and Becker (2003). FARO 61 had the highest of water uptake ratio value. Amylose content might be responsible for high water uptake ratio, as Frei et al. (2003) reported that rice with high amylose content tends to absorb more water during cooking. From table 5, there was a negative correlation $(\mathrm{p}<0.01)$ between cooking time and $\mathrm{L}^{*}(\mathrm{r}=-0.711)$ while a positive correlation existed between cooking time and water uptake ratio $(r=0.874)$. This implies that the higher the $\mathrm{L}^{*}$, the shorter the cooking time while increase in cooking time increases water uptake ratio.

\section{Conclusions}

From results, it can be concluded that the new rice varieties differ significantly in some of their physical, milling and cooking properties. Size and shape classification showed that FARO 44, FARO 52, FARO 60 and FARO 61 were very long-slender paddy and medium-slender milled rice respectively. FARO 60 had the highest head milled rice and lowest broken milled rice while FARO 44 had the longest cooking time. Water uptake ratio was found to be highest in FARO 61 . Positive correlation occurred between milling re- covery and head milled rice while negative correlation existed between cooking time and $\mathrm{L}^{*}$. The results showed the reason why parboiling is recommended as an alternative option to increase the milling recovery and head milled rice during rice processing.

\section{Acknowledgements}

The authors would like to heartily thank the National Cereal Research Institute, Baddeggi, Nigeria for providing the laboratory facilities for this research work and also, staff of Food Technology and Value Addition, most especially Mr. Bitrus Akukipi.

\section{References}

Aboubakar, Njintang, Y. N., Scher, J., \& Mbofung, C. M. F. (2008). Physicochemical, thermal properties and microstructure of six varieties of taro (colocasia esculenta 1. schott) flours and starches. Journal of Food Engineering, 86(2), 294-305. doi:10.1016/ j.jfoodeng.2007.10.006

Anonymous. (1997). Annual report for 1997. Bangladesh Rice Research Institute, Gazipur, 24-25.

Correa, P. C., da Silva, F. S., Jaren, C., Afonso Junior, P. C., \& Arana, I. (2007). Physical and mechanical properties in rice processing. Journal of Food Engineering, 79(1), 137-142. doi:10.1016/j.jfoodeng.2006.01. 037

Danbaba, N., Anounye, J. C., Gana, A. S., Abo, M. E., \& Ukwungwu, M. N. (2011). Grain quality characteristics of ofada rice (oryza sativa 1.): cooking and eating quality. International Food Research Journal, 18(2), 629-634. Retrieved from http://www.ifrj. upm . edu . my / $18 \%$ 5C \% 20(02 ) \%5C \% 202011/(23)\%5C\%20IFRJ-2010-105.pdf

Danbaba, N., Anounye, J. C., Gana, A. S., Abo, M. E., Ukwungwu, M. N., \& Maji, A. T. (2012). Physical and pasting properties of 'ofada' rice (oryza sativa 1.) varieties. Nigerian Food Journal, 30(1), 18-25. doi:10. 1016/S0189-7241(15)30009-6 
Dipti, S. S., Bari, M. N., \& Kabir, K. A. (2003). Grain quality characteristics of some beruin rice varieties of bangladesh. Pakistan Journal Nutrition, 2(4), 242-245. Retrieved from http : / / scialert. net / qredirect . php ? doi = pjn . 2003 . $242.245 \%$ 5 C\&linkid $=$ pdf

Firouzi, S., Alizadeh, M. R., \& Minaei, S. (2010). Effect of the size of perforated screen and blade-rotor clearance on the performance of engleberg rice whitener. African Journal of Agricultural Research, 5(9), 941-946. doi:10.5897/AJAR09.542

Fitzgerald, M. A., McCouch, S. R., \& Hall, R. D. (2009). Not just a grain of rice: the quest for quality. Trends in Plant Science, 14(3), 133-139. doi:10.1016/j.tplants.2008.12.004

Frei, M., Siddhuraju, P., \& Becker, K. (2003). Studies on the in vitro starch digestibility and the glycemic index of six different indigenous rice cultivars from the philippines. Food Chemistry, 83(3), 395-402. doi:10 . 1016/S0308-8146(03)00101-8

IRRI - International Rice Research Institute. (1980). Alkali digestion. Standard Evaluation for Rice: International Rice Testing Program, 2nd Edition, IRRI, Manila, 4344.

Izawa, T. (2008). The process of rice domestication: a new model based on recent data. Rice, 1(2), 127-134. doi:10.1007/s12284008-9014-7

Jain, R. K. \& Bal, S. (1997). Properties of pearl millet. Journal of Agricultural Engineering Research, 66(2), 85-91. doi:10.1006/jaer. 1996.0119

Juliano, B. O. (2003). Rice chemistry and quality. Philippine rice research institute Manila, Philippines.

Kaur, M., Kaushal, P., \& Sandhu, K. S. (2013). Studies on physicochemical and pasting properties of taro (colocasia esculenta l.) flour in comparison with a cereal, tuber and legume flour. Journal of Food Science and Technology-mysore, 50(1), 94-100. doi:10. 1007/s13197-010-0227-6

Mckenzie, K. S. \& Rutger, J. N. (1983). Geneticanalysis of amylose content, alkali spreading score, and grain dimensions in rice. Crop Science, 23(2), 306-313.
Mir, S. A., Bosco, S. J. D., \& Sunooj, K. V. (2013). Evaluation of physical properties of rice cultivars grown in the temperate region of india. International Food Research Journal, $20(4)$.

Mohsenin, N. N. (1970). Physical properties of plant and animial materials. structure, physical characterisitics and mechanical properties. New York, USA: Gordon \& Breach Science Publishers Inc.

Nalladurai, K., Alagusundaram, K., \& Gayathri, P. (2002). Airflow resistance of paddy and its byproducts. Biosystems Engineering, 83(1), 67-75. doi:10.1006/bioe.2002.0091

Oko, A. O. \& Ubi, N., B. E. Dambaba. (2012). Rice cooking quality and physico-chemical characteristics: a comparative analysis of selected local and newly introduced rice varieties in ebonyi state, nigeria. Food and Public Health, 2(1), 43-49. doi:10.5923/j. fph.20120201.09

Rather, T. A., Malik, M. A., \& Dar, A. H. (2016). Physical, milling, cooking, and pasting characteristics of different rice varieties grown in the valley of kashmir india. Cogent Food \& Agriculture, 2(1), 1178694. doi:10. 1080/23311932.2016.1178694. eprint: http: / / dx . doi .org / 10 . 1080 / 23311932 . 2016. 1178694

Ravi, U., Menon, L., Gomathy, G., Parimala, C., \& Rajeshwari, R. (2012). Quality analysis of indigenous organic asian indian rice variety- salem samba. Indian Journal of Traditional Knowledge, 11(1), 114-122.

Shittu, T. A., Olaniyi, M. B., Oyekanmi, A. A., \& Okeleye, K. A. (2012). Physical and water absorption characteristics of some improved rice varieties. Food and Bioprocess Technology, 5(1), 298-309. doi:10.1007/ s11947-009-0288-6

Simonyan, K. J., El-Okene, A. M., \& Yiljep, Y. D. (2007). Some physical properties of samaru sorghum 17 grains. Agricultural Engineering International: the CIGR Ejournal Manuscript FP 07008, 9, 1-15.

Singh, M., Kaur, P., \& Singh, J. (2015). Physical properties and milling characteristics of different paddy varieties. International Journal for Science and Advance Research in Technology, 1, 59-63. 
Singh, N., Kaur, L., Sodhi, N. S., \& Sekhon, K. S. (2005). Physicochemical, cooking and textural properties of milled rice from different indian rice cultivars. Food Chemistry, 89(2), 253-259. doi:10.1016/j.foodchem. 2004.02 .032

Thakur, A. K. \& Gupta, A. K. (2006). Water absorption characteristics of paddy, brown rice and husk during soaking. Journal of Food Engineering, 75(2), 252-257. doi:10. 1016/j.jfoodeng.200504.014

Varnamkhasti, M. G., Mobli, H., Jafari, A., Keyhani, A. R., Soltanabadi, M. H., Rafiee, S., \& Kheiralipour, K. (2008). Some physical properties of rough rice (oryza sativa 1.) grain. Journal of Cereal Science, 47(3), 496-501. doi:10.1016/j.jcs.2007.05.014

Wiset, L., Srzednicki, G., Driscoll, R., Nimmuntavin, C., \& Siwapornak, P. (2001). Effects of high temperature drying on rice quality. Agricultural Engineering International: the CIGR Journal of Scientific Research and Development. Manuscript FP 01 003, 3, 1-10. Retrieved from https:// core.ac.uk/download/pdf/4908748.pdf

Wozniak, W. (2001). Mechanical properties of wheat grain in relation to internal cracks. International Agrophysics, 15, 59-64.

Zareiforoush, H., Hosseinzadeh, B., Adabi, M. E., \& Motavali, A. (2011). Moisture-dependent physical properties of paddy grains. Journal of American Science, 7(7), 175-182. doi:10.7537/marsjas070711.30

Zareiforoush, H., Komarizadeh, M. H., \& Alizadeh, M. R. (2009). Effect of moisture content on some physical properties of paddy grains. Research Journal of Applied Sciences, Engineering and Technology, 1(3), 132-139. Retrieved from http: / / maxwellsci . com / print / rjaset / (3 ) 132 139.pdf 